\title{
The potential of Raman microscopy and Raman imaging in plant research
}

\author{
Notburga Gierlinger ${ }^{\mathrm{a}, *}$ and Manfred Schwanninger ${ }^{\mathrm{b}}$ \\ ${ }^{a}$ Max-Planck-Institute of Colloids and Interfaces, Department of Biomaterials, Potsdam, Germany \\ ${ }^{\mathrm{b}}$ BOKU - University of Natural Resources and Applied Life Sciences, Department of Chemistry, \\ Vienna, Austria
}

\begin{abstract}
To gain a better understanding on structure, chemical composition and properties of plant cells, tissues and organs several microscopic, chemical and physical methods have been applied during the last years. However, a knowledge gap exists about the location, quantity and structural arrangement of molecules in the native sample or what happens on the molecular level when samples are chemically or mechanically treated or how they respond to mechanical stress. These questions need to be answered to optimise utilization of plants in food industry and pharmacy and to understand structure-function relationships of plant cells to learn from natures unique. Advances in combining microscopy with Raman spectroscopy have tackled this problem in a non-invasive way and provide chemical and structural information in situ without any staining or complicated sample preparation. In this review the different Raman techniques (e.g. near infrared Fourier Transform Raman spectroscopy (NIR-FT), resonance Raman spectroscopy, surface-enhanced Raman spectroscopy) are briefly described before approaches in plant science are summarised. Investigations on structural cell wall components, valuable plant substances, metabolites and inorganic substances are included with emphasis on Raman imaging. The introduction of the NIR-FT-Raman technique led to many applications on green plant material by eliminating the problem of sample fluorescence. For mapping and imaging of whole plant organs (seeds, fruits, leaves) the lateral resolution $(\sim 10 \mu \mathrm{m})$ of the NIR-FT technique is adequate, whereas for investigations on the lower hierarchical level of cells and cell walls the high resolution gained with a visible laser based system is needed. Examples on high resolution Raman imaging are given on wood cells, showing that changes in chemistry and orientation can be followed within and between different cell wall layers having dimensions smaller than $1 \mu \mathrm{m}$. In addition imaging the distribution of amorphous silica is shown on horsetail tissue, including an area scan from a cross section as well as a depth profiling within a silica rich knob of the outer stem wall.
\end{abstract}

Keywords: Cellulose, cell walls, chemotaxonomy, crystallinity, hemicelluloses, inorganic substances, lignin, micromechanical studies, minerals, molecular stress, plant fibres, plant metabolites, silica, terpenes

\section{Introduction}

The main spectroscopic techniques to detect vibrations in molecules are based on the processes of infrared absorption and Raman scattering. While Raman scattering involves excitation of a molecule by inelastic scattering with a photon (from a laser light source), infrared spectroscopy typically involves photon absorption, with the molecule excited to a higher vibrational energy level [1]. Raman scattering depends on changes in the polarisability due to molecular vibrations, while infrared absorption depends

\footnotetext{
* Corresponding author: Notburga Gierlinger, Max-Planck-Institute of Colloids and Interfaces, Department of Biomaterials, D-14424 Golm, Germany. Tel.: +49 331567 9426; Fax: +49 331567 9402; E-mail: Gierlinger@mpikg.mpg.de.
} 
on changes in the intrinsic dipole moments induced by molecular vibrations [2]. Raman and infrared spectroscopy thus provide "complementary" information about the molecular vibrations. While infrared (IR) spectroscopy has been established for decades as a useful tool for structure elucidation and quality control in various industrial applications, the use of Raman spectroscopy was restricted for a long time primarily to academic research. Nowadays both spectroscopic methods are widely used to gain information on chemical structures, to identify substances from the characteristic spectral patterns ("fingerprinting") and to determine quantitatively or semi-quantitatively the amount of a substance in a sample. The identification and quantification of valuable plant substances by IR and Raman spectroscopy was reviewed very recently by Schulz and Baranska [3].

Due to the strong dipole moment of water, which results in a strong signal, applications of IR spectroscopy were focused on dry material. Attenuated total reflectance (ATR) techniques have also evolved rapid IR measurements of many liquids and solvent extracts. Contrary to the strong absorption in IR, water has only weak Raman scattering properties making this technique more suitable to perform in situ studies of fresh plant material. Raman scattering is in general less widely used than infrared absorption, mainly due to problems with sample degradation and fluorescence. However, in the past years a renaissance of Raman spectroscopy was triggered by recent advancement in laser technology, by the design of very efficient filters to suppress elastically scattered Rayleigh light, by the development of extremely sensitive detectors and new methodological approaches for enhancing signal intensity [4]. These advances, together with the ability to examine aqueous solutions and samples without any preparation have led to a rapid growth in the application of the technique, especially in combination with microscopy [5,6]. Besides classical fields in chemistry new fields have opened e.g. in art and archaeology [7], in food science [8-11], biology [12-17], pharmaceutical and medical [18-22] and biomaterial research [23-26].

The approaches developed in plant science will be summarised in this review after some general information on the principle, instrumentation and limitations of the different Raman techniques. In the first section emphasis is laid on plant cell walls and structural aspects, including investigations of plant fibres and wood. The potential of the Raman mapping technique will be illustrated for wood cell walls. In the second part the research on green plant tissues and plant organs will be presented, including the investigations on the distribution and characterisation of natural plant products, e.g. essential oils, carotenoids and alkaloids. Finally investigations on mineral substances in plants will be mentioned and completed with recent results on Raman imaging of silica in horsetail.

\section{Principle, instrumentation and limitations}

A Raman spectrum is usually obtained through inelastic scattering of coherent monochromatic light from a laser, so that it can be focussed on a small spot. Thus it has long been recognised as having potential as a microscopic technique [27], which can also be made confocal and thus allow depth profiling. Most Raman microscopes use a beam-splitter to inject the laser into the collection axis, and "infinitycorrected" objective lenses to permit a collimated beam path within the microscope. There are several variations on the design, but most of them direct the laser beam through the objective lens and collect scattered light through the same objective lens in a $180^{\circ}$ backscattered geometry, followed by notch or edge filters that remove most of the intense elastic Rayleigh scattering [2]. The spatial resolution is determined by the optical characteristics of the objective lens and associated optics, and is especially large when coupled to the confocal technique. The laws of diffraction provide a theoretical limit to the spatial resolution, with a strong dependence on the wavelength $(\lambda)$ of the laser and the numerical aperture 
(NA) of the objective $(\Delta x=0.61 \lambda / \mathrm{NA})$ [28]. In practice the spatial resolution achieved is less than the theoretical limit, for example Agarwal [29] observed a spatial resolution of 1.6 micrometers $(\mu \mathrm{m})$ for a $514.5 \mathrm{~nm}$ excitation based Raman microprobe and about $10 \mu \mathrm{m}$ for a $1064 \mathrm{~nm}$ based system, using a $100 \times$ microscopic objective.

Classical dispersive multichannel Raman spectrometers are usually composed of laser with wavelength in the visible range (e.g. $\mathrm{Ar}^{+}, \mathrm{He}-\mathrm{Ne}, \mathrm{Kr}^{+}$, doubled $\mathrm{Nd}$ :YAG lasers) for excitation, a dispersive spectrometer and a charge coupled device detector (CCD) for detection [2,30]. This system enables high spatial resolution when coupled to a confocal microscope equipped with objectives with high numerical apertures. Depending on the sample or sample impurities the serious problem of fluorescence may hinder measurements or even make measurements impossible if a laser in the visible range is used. Especially in the analysis of "real life" samples, the fluorescence may mask the Raman spectra completely. When Raman spectroscopy is moved from the visible to the near-infrared (NIR) range, fluorescence virtually disappears as electronic absorption bands are much less probable in this region [31]. The use of Nd:YAG laser radiation at $1064 \mathrm{~nm}$ coupled with interferometers (involving Fourier transformations) led to socalled near infrared Fourier Transform (NIR-FT) Raman spectrometers [31], which allow measurements of a wide variety of samples [32-36]. Besides having a lower spatial resolution, another consequence of moving to the NIR is that hydrogen-containing compounds, whether sample or solvent, have absorption bands due to overtones and combinations of the fundamental vibrations. This can result in a reduction in the intensity of Raman-scattered light in the range of the absorption bands and thus a drop in the detected intensity. Furthermore the absorption of the exciting radiation can result in thermal emission. Nevertheless the quality of the spectra can be improved by optimising the sampling arrangement as discussed in [35].

The detection of molecules present in very low concentrations is limited, since the Raman effect gives weak signals as only a small number of the incident photons are inelastically scattered. To circumvent this problem, special Raman signal-enhancing techniques can be applied. The two most prominent approaches are the resonance Raman effect and the surface-enhanced Raman scattering (SERS) [2]. The resonance condition in resonance Raman spectroscopy arises when the exiting laser wavelength is adjusted to the electronic absorption band, causing the vibrational modes involved in the electronic transition to be selectively enhanced (by a factor of up to 100 compared to non-resonant excitation). The SERS effect corresponds to the enhancement (by a factor of up to $10^{7}$ ) of the Raman scattering of a molecule situated in the vicinity of nano-sized metallic particles (e.g. Ag or Au) [37-39]. Although the exact reason for such dramatic improvement is still under discussion [22], it is known that there are two possible reasons (a) the enhancement of polarizability, and (b) the enhancement of electrical field, since intensity of Raman signal is proportional to the square of electric dipole moment. One disadvantage of SERS is the difficulty of spectra interpretation. Additionally, because of chemical interactions with the metal surface, certain peaks, which are strong in conventional Raman, might not be present in SERS at all. A non-linear character of signal intensity as a function of concentration complicates things even further. The surface-enhanced resonance Raman spectroscopy (SERRS) technique utilizes both surfaceenhancement effect and Raman resonance effect so the resulting enhancement in Raman signal intensity can be as high as $10^{14}$. The main advantage of SERRS is that the spectra resemble very much regular resonance Raman spectra, which makes it much easier to interpret. SERRS has also been used in imaging studies $[40,41]$.

Besides the linear Raman spectroscopic techniques, inelastic, non-linear scatterings in which the vibrational degrees of freedom in molecular systems are measured have been developed. The impressive 
progress of femto-second lasers in the 1990s resulted in a breakthrough of non-linear Raman spectroscopy such as coherent anti-stokes Raman scattering (CARS) [4]. CARS microscopy is a promising label-free imaging technique for biological samples [42-46].

One of the central problems in Raman spectroscopy is the fluorescence. As mentioned earlier it can be suppressed or at least substantially reduced by selecting the excitation wavelength in the near infrared. The problem of near-UV-visibly excited Raman spectroscopy can also be circumvented by probing well below the fluorescence emission in the ultraviolet (UV) region [47-49]. However, this method often leads to resonance enhancement of several sample constituents simultaneously and this may be undesirable when detecting species at low concentrations or where constituent selectivity is desired. To achieve selectivity through the resonance enhancement, a laser with an excitation wavelength in the near-UVvisible region is necessary requiring suppression techniques to eliminate the detrimental effects of the fluorescence background on the Raman signal [50]. Several linear Raman techniques have been demonstrated to reduce the fluorescence problem including shifted excitation Raman difference spectroscopy (SERDS) [51], polarization modulation [52], shifted spectra [53,54], Fourier transform filtering [53], temporal gating [54,55], but the techniques have some limitations [56]. An effective rejection device based on a 4 picosecond optical Kerr shutter has been developed [57,58] for separating Raman light from fluorescence in the time domain. The fluorescence suppression ratio achievable by the technique depends on the fluorescence lifetime and can be up to $10^{5}$ for long-lived fluorescence species $(>1 \mu \mathrm{s})$. The specifications of the gate allow a rejection ratio of $10^{-5}$ in the closed state and a usable spectral range from 300 to $700 \mathrm{~nm}$. To enhance the performance of this device further for the case where an intense fluorescence background is still present after the Kerr gate, a new approach that combines the Kerr gating rejection technique with SERDS has been developed [50]. The Kerr gate directly rejects fluorescence while the probe shifted technique accesses the photon shot noise level within the residual fluorescence [50,51]. Moreover, it was found that the presence of the SERRS-active metallic Ag surface dramatically reduced the high fluorescence yield from plant pigments [59], a serious problem that has prevented detection of resonance Raman scattering signals in the past [60].

Beside single spectra acquisition the advent of two-dimensional detectors combined with precise $x-y-z$ motor stages permits a variety of efficient methods categorized broadly as Raman imaging and mapping techniques resulting in a sample image based on spectroscopic information [61]. Basically Raman imaging methods can be classified in two categories, referred to as "parallel- or direct-imaging" or "series-imaging" [62]. The direct-imaging technique results in the immediate production of a complete two-dimensional (2D) image at a chosen wavelength which is characteristic of a molecular compound within the specimen and does not necessitate additional data processing [62]. On the other hand, series-imaging techniques require image reconstruction after collecting spectral information [62], e.g. the diffraction-limited spot of the laser is moved line by line over a defined area and at every defined point (pixel) a spectrum over the entire wavenumber range is acquired. Spectral images can be calculated afterwards by integrating the intensity of defined wavenumber ranges (e.g. $[13,63,64])$ or by using multivariate approaches [65]. The series-imaging is advantageous, because a spectrum comprising the whole wavenumber range is available at every pixel and can avoid misinterpretation of the image data and give further insights. In addition to lateral $x-y$ mappings also depth scans $(x-z)$ are possible in the confocal mode, but for depth profiling the use of immersion objectives is recommended to minimise errors due to refraction at the sample surface $[66,67]$.

The Raman mapping experiments shown in this review were done with a visible laser based system, described in detail together with the sample preparation of the wood cell walls in $[63,68]$. For the area scan on wood cell walls (Fig. 2) an oil immersion objective (Nikon, $100 \times, \mathrm{NA}=1.25$ ) and for the 
area and depth scan on horsetail (Fig. 4) a water immersion objective (Nikon, $60 \times, \mathrm{NA}=1$ ) was used. Spectra were acquired every $0.25 \mu \mathrm{m}$ with an integration time of $1 \mathrm{~s}$ on the wood sample (Fig. 2) and every $1 \mu \mathrm{m}$ with $2 \mathrm{~s}$ integration time on the horsetail sample.

\section{Applications on plants}

Raman spectroscopy is used for probing structure, dynamics and function of biomolecules. By combining this technique with microscopy, molecular information can be obtained with high spatial resolution, samples of microscopic size can be analysed directly wet or dry, and in many cases this can be done non-destructively. A number of organic compounds and functional groups can be identified by their unique spectral pattern, and the intensity of the bands may be used for the calculation of the relative concentration in the sampled entity. Both qualitative and quantitative information can be obtained using microspectroscopy and also information regarding the orientation of functional groups.

\subsection{Plant fibres and cell walls}

The shape and mechanical strength of the living plants is maintained by structural components organised in complex patterns in the plant cell walls. While primary cell walls must be capable of growth and therefore be flexible and elastic, secondary cell walls in fibres and wood are rigid to avoid buckling [69]. The functional characteristics of cell walls depend not only on the composition of the cell wall polymers, but also on fine details of their macromolecular structure and conformation, and on their highly ordered architecture at scales from a few nanometers (i.e. just above the molecular scale) to several microns. Much of this fine detail is lost when cell-wall polymers are fractionated and/or solubilised to be examined by the classical chemical techniques. Therefore spectroscopic approaches play an important role to examine plant cell walls in their native state. Not only the chemical composition per se is of interest, but also the conformation and the composition in relation to different cell wall layers as well as the orientation of the polymers and changes during treatment and deformation.

Less work has been done on primary walls [70] and in the following the focus will be on secondary walls of plant fibres and wood.

\subsubsection{Cellulosic plant fibres}

Raman applications on plants began with the investigation of cellulose [71-73], the most important skeletal component in plants [74]. Early Raman microprobe studies on native cellulose fibres (Valonia, Cladophora, cotton and ramie) were important basic studies to understand the spectra and structure of native celluloses and to assign the bands in the complex spectra [72,73]. During the last decade the feasibility of Raman spectroscopy to investigate natural plant fibres non-destructively was demonstrated for several cellulose fibres e.g. flax [75-80], cotton [77,81], jute, ramie, kapok, sisal and coconut fibres [77]. The chemical composition of these fibres varies between species and somewhat according to growth conditions, but their main constituent is cellulose (64-91\%) and the rest water, lignin and pectin [77]. Studies go from general characterisation of fibres $[76,77]$ to analysis following the molecular changes during mechanical processing [34] and chemical treatments [78].

One of the first Raman imaging studies in plant research was done on flax stem tissue [76]. Using the NIR-FT-Raman technique area maps were collected in 6 to $10 \mu \mathrm{m}$ steps and chemical profiles calculated by integration over specific spectral regions. By this no information was gained on the cellular level, but the major components (cellulose, lignin, non-cellulosic polysaccharides) in the different anatomical tissue types (epidermal tissue, bast, fibres and core) could be investigated [76]. 


\subsubsection{Lignified cell walls (wood)}

Raman microprobe studies on wood began not much later than on cellulose fibres and brought important insight into the macromolecular organisation and compositional variability of the cell wall [82-85]. Wood consists of 40 to $50 \%$ cellulose, associated with a mixture of hemicelluloses (20-30\%), lignin (20-35\%) an aromatic system composed of phenylpropane units, extractives (2-20\%) and ash (0.2-3\%) [86,87]. Excitation of aromatic and conjugated lignin structures with deep ultra violet (UV) light gives resonance-enhanced Raman signals and enabled to investigate lignin structures and detection of lignin trace amounts [88-92]. A few of the substructures of lignin are capable of exhibiting a pre-resonance effect when visible excitation is used and in some studies on lignocellulosic material laser induced fluorescence was encountered thus limiting applications [29]. The field of lignocellulosics thus benefited from the development of the NIR-FT-Raman method. It enabled, for example, the study of changes in lignin structure in situ in the xylem of stems of genetically manipulated tobacco plants [93].

In order to interpret the Raman spectrum of a multicomponent material such as wood, not only the contribution of each component needs to be identified, but also the latter needs to be assigned to componentspecific moieties and/or functional groups. An important study to identify contributions of the wood polymers in the spectrum of black spruce (Picea mariana) was done by Agarwal and Ralph [94]. Most of spruce Raman features could be assigned to cellulose and lignin, whereas contributions of hemicelluloses occurred at similar wavenumbers to cellulose and could not be clearly distinguished. To investigate changes at the hierarchical level of individual cells and/or cell wall layers, the use of visible laser excitation is preferential as a higher spatial resolution can be achieved. Laser-induced lignin fluorescence can be limited by sampling under water and/or oxygen [29], an optical Kerr gate [95,96], and using confocal mode $[29,63]$. A study with a visible laser-based system on $1.6 \mu \mathrm{m}$ regions from 30 cell corner middle lamellae in white birch and black spruce indicated that the relative concentration of lignin to cellulose varied considerably [97]. In the last years the potential of Raman imaging was shown on wood cell walls [63,64,98]. A 785-nm near-IR laser-based Raman system was applied to study beech cell walls [98], but also higher resolution, 633-nm [64] and 532-nm [63] visible laser-based confocal Raman microscopes were used to investigate the wooden cell walls with a spatial resolution below $1 \mu \mathrm{m}$. After mapping a sample area of interest Raman images can be calculated by integration over bands assigned to e.g. lignin or cellulose (Fig. 1) to visualize the distribution of the wood cell wall polymers (Fig. 2A-F) [63,64]. In the lignin image (integration range 1540 to $1760 \mathrm{~cm}^{-1}$ ) of a cross-section of poplar wood (Populus sp.) the compound middle lamella (middle lamella and primary cell wall, CML) and the cell corners (CC) show high intensity (bright yellow) due to higher lignin content compared to the secondary cell wall (S2) (Fig. 2A). The secondary wall of the vessel in the left bottom of the image also shows a higher degree of lignification. This technique enabled furthermore to localise a small lignified layer $(0.5 \mu \mathrm{m})$ towards the lumen in the cellulosic gelatinous layer of poplar tension wood fibres [63]. In another similar study significant variation of the lignin content was suggested within the S2 of black spruce wood [64].

Spectra can be extracted from single points and cell wall layers (Fig. 3A-B) for further evaluation, and band intensities can be plotted along drawn lines, e.g. across a cell wall [63]. Beside spectral changes, the extracted average spectra of the cell corner, the secondary cell wall of fibres and the vessel show big differences in the background level, which increases with higher lignin bands in the vessel wall and the cell corner (Fig. 3A).

Cellulose distribution can be followed by taking the band regions around $380 \mathrm{~cm}^{-1}[64,98]$, $1097 \mathrm{~cm}^{-1}$ and $2898 \mathrm{~cm}^{-1}$ [64] into account (Fig. 1). Only the $380 \mathrm{~cm}^{-1}$ band region can be unambiguously assigned to cellulose, whereas the other two regions have definite but small contributions 


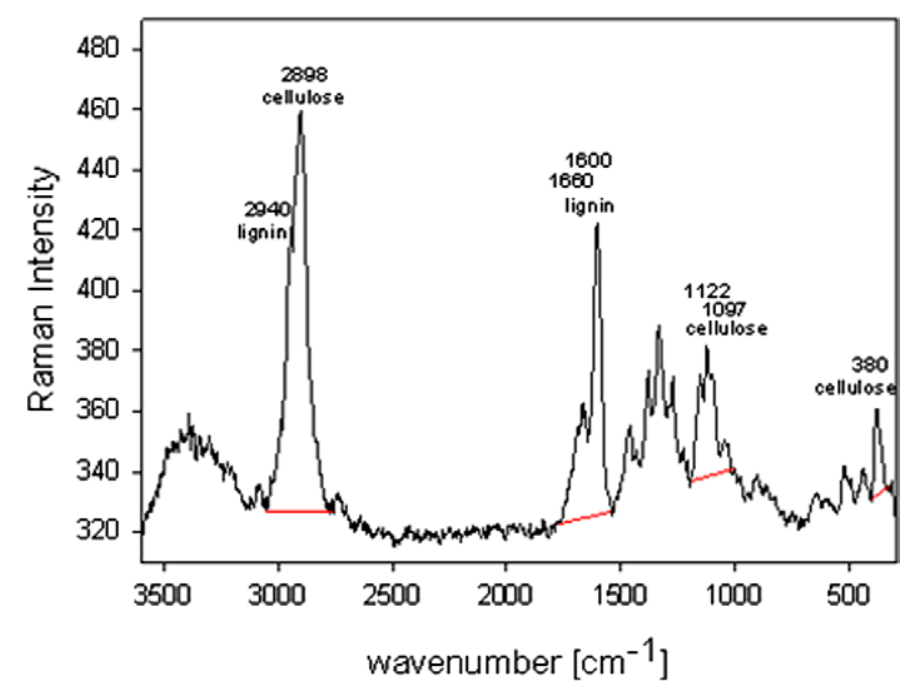

Fig. 1. Average Raman spectrum of the secondary cell wall of poplar wood. The regions chosen to calculate the chemical images in Fig. 2 are indicated.

from lignin and/or hemicelluloses [64,94]. Nevertheless, the similarity of the three band profiles indicated that any small contributions from lignin does not significantly distort the results; and due to an enhanced signal-to-noise ratio the more intense bands at 1097 and $2898 \mathrm{~cm}^{-1}$ might be preferential [64]. In our imaging example we result in three different cellulose images by using the three cellulose regions (Fig. 2B-D). Choosing the low intensity band around $380 \mathrm{~cm}^{-1}$ results in a higher cellulose content in the secondary cell wall than in the CML, but the cell corners known to be almost cellulose free also show high intensities (Fig. 2B). This is explained by the fact that the lignin rich cell corner spectra show a much higher fluorescence background accompanied by a lower signal to noise ratio (Fig. 3A). Thus low intensity bands have to be chosen with care for image calculation, if big changes in background and signal to noise ratio are observed within the investigated region (Fig. 3A). Integrating over a wider range (1178 to $1001 \mathrm{~cm}^{-1}$ ) comprising different cellulose bands and only small lignin contributions the CCs and CML show less intensity, proving that the lignin contribution has little influence and allowed the imaging of almost cellulose free CCs (Fig. 2C). Choosing the area comprising bands attributed to $\mathrm{CH}$-stretching of cellulose $\left(2898 \mathrm{~cm}^{-1}\right)$ and lignin $\left(2940 \mathrm{~cm}^{-1}\right)$ reveals that cellulose contributions predominate, because secondary walls are emphasised in comparison to the lignin rich CML and CC (Fig. 2D). In all three cellulose images (Fig. 2B-D) intensity changes are observed within the secondary cell wall regions. A closer look at the extracted spectra revealed that band heights of the different cellulose bands do not change uniformly, but changing band height ratios are observed (Fig. 3B). These intensity changes clearly derive from effects due to orientation $[63,68]$ and will be discussed in the next chapter.

\subsubsection{Orientation of cell wall molecules}

Over the past 40 years the technique of polarised Raman spectroscopy has been developed as an important method to study molecular orientation distributions in polymers [99]. Also in biopolymers the dependence of band intensities on the polarisation of the incident light relative to the orientation of the molecule can reveal the directional character of many of the vibrational modes. The intensity of the $\nu_{\mathrm{s}}(\mathrm{C}-\mathrm{O}-\mathrm{C}), \nu(\mathrm{CH})$ and $\nu_{\mathrm{s}}\left(\mathrm{CH}_{2}\right)$ modes, mainly related to $\beta(1 \rightarrow 4)$ glycosidic linkages of the cellulose 

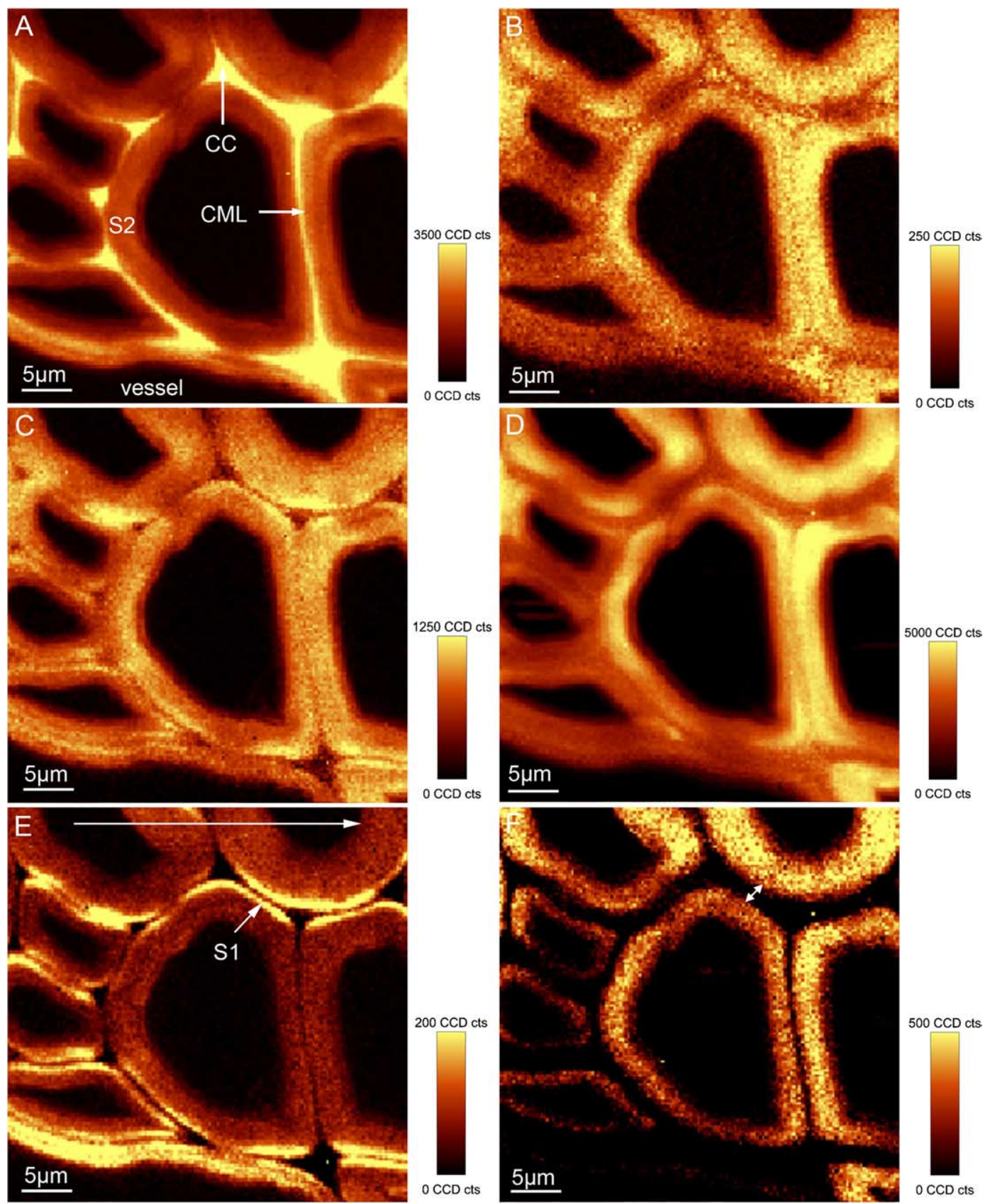

Fig. 2. (A-F) Raman images $(40 \mu \mathrm{m} \times 40 \mu \mathrm{m})$ of a cross-section of poplar wood calculated by integrating from 1540 to $1760 \mathrm{~cm}^{-1}$ (A, lignin), 352-401 $\mathrm{cm}^{-1}$ (B, cellulose), 1178 to $1001 \mathrm{~cm}^{-1}$ (C, cellulose), 2769 to $3043 \mathrm{~cm}^{-1}$ (D, cellulose) and very restricted wavenumber ranges to accentuate the orientation sensitive cellulose band at $1097 \mathrm{~cm}^{-1}\left(1114\right.$ to $\left.1079 \mathrm{~cm}^{-1}, \mathrm{E}\right)$ and $2898 \mathrm{~cm}^{-1}$ (2931 to $\left.2819 \mathrm{~cm}^{-1}, \mathrm{~F}\right)$. The big arrow in E indicates the direction of laser polarisation. 

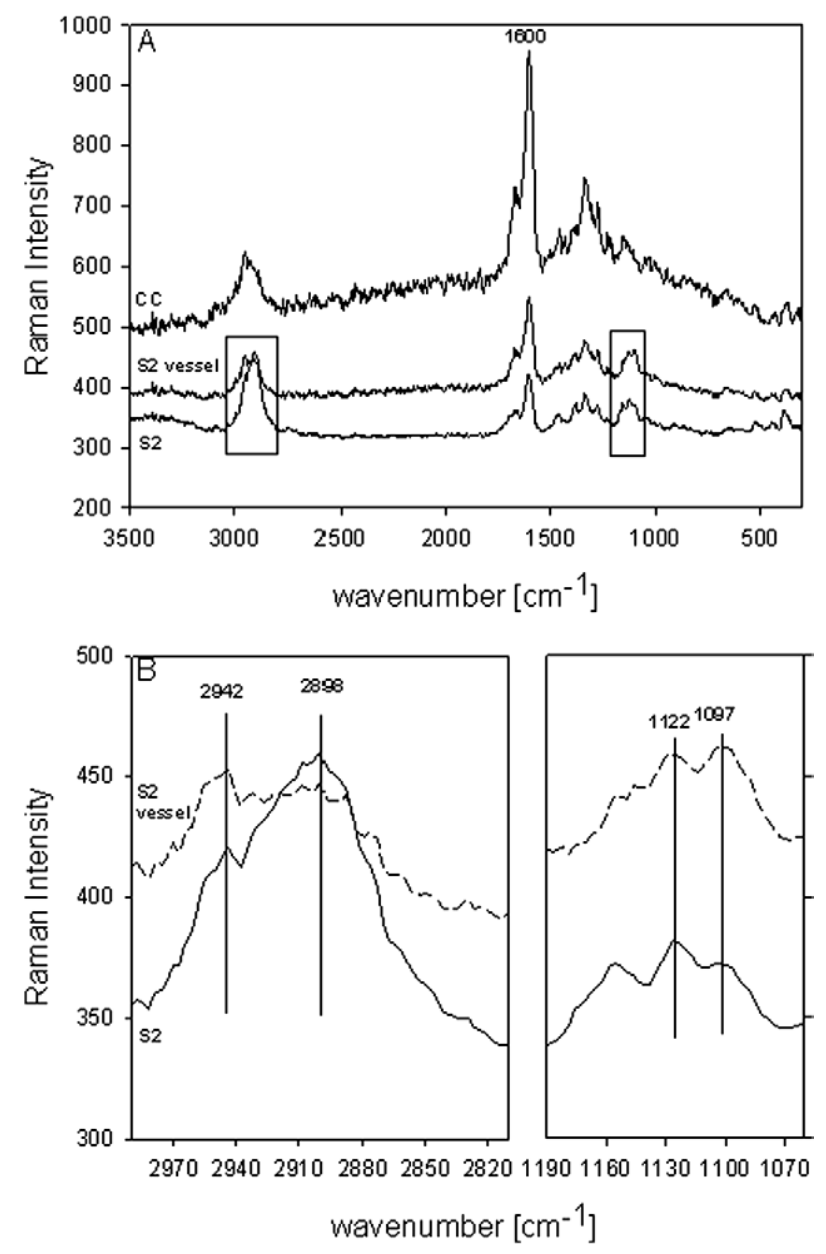

Fig. 3. (A, B) Extracted average Raman spectra (A) of the cell corner (CC), the S2 of the fibres (S2) and of the vessel (S2 vessel) and a zoom into regions of interest (B).

skeletons, to methine groups of the glucopyranose rings as well as to the methylene groups of the glucopyranose side show clear orientation-dependent vibrational behaviour. Spectra acquired with different polarisation of the incident light relative to the axis of cellulose fibres gave evidence for molecular orientation in native cellulosic fibres $[73,75]$ and supported the interpretation of the vibrational spectrum of cellulose [72]. Experiments on wood sections with the laser parallel and perpendicular to the fibre axes evidenced that cell wall components are highly organised [82,100]. Not only the cellulose was found to be oriented parallel to the fibre axis, but also the phenyl ring of lignin is preferentially oriented in the plane of the cell wall surface as seen by intensity changes of the band at $1600 \mathrm{~cm}^{-1}$ [82]. Recently also the net orientation of macromolecules in the epidermal cell wall of wheat stems was investigated: cellulose was found to be oriented parallel, whereas xylan and the phenylpropane units of lignin tend to lie perpendicular to the longitudinal axis of the cells [101].

When polarised laser light is used in combination with Raman imaging care has to be taken to interpret every intensity change due to concentration differences, as the orientation of the molecules with respect to the direction of the laser polarisation may also affect intensity. Although this may compli- 
cate data interpretation, it can on the other hand provide an insight into changes of orientation of the molecule within the sample [63,68]. Integrating over narrow areas comprising the cellulose bands most affected by orientation changes $\left(\nu_{\mathrm{s}}(\mathrm{C}-\mathrm{O}-\mathrm{C})\right.$ at $1097 \mathrm{~cm}^{-1}$ and $\nu_{\mathrm{s}}(\mathrm{CH})$ at $\left.2898 \mathrm{~cm}^{-1}\right)$ cell wall layers with different orientation can be worked out (Fig. 2E,F). A small layer $(<0.5 \mu \mathrm{m})$ representing the S1 is clearly separated from the S2 and the CML in the direction of the laser polarisation. Also the S2 of the vessel shows higher intensity than the $\mathrm{S} 2$ of the fibres (Fig. 2E). Integrating over the $\nu_{\mathrm{s}}(\mathrm{CH})$ band emphasises the $\mathrm{S} 2$ of the fibres, but in $y$-direction the size of the gap between the double cell wall is broader (Fig. 2F) as the $\mathrm{S} 1$ is included due to low band intensities in the S1. These effects are explained by the fact that in the S2 the cellulose is aligned parallel to the fibre axes, whereas in the S1 and in the vessel wall the cellulose is aligned in an angle (probably greater than $45^{\circ}$ ). The spectral explanation is that in the investigated cross-section if cellulose is aligned parallel to the fibre axis the $\nu_{\mathrm{s}}(\mathrm{C}-\mathrm{O}-\mathrm{C})$ is low, because we look perpendicular on the backbone. Whereas the side chain methylene groups, which are perpendicularly arranged with respect to the cellulose molecule, are in plane with the incident light and show high intensity [100]. When cellulose is aligned with a high angle in respect to the fibre axis the $\mathrm{C}-\mathrm{O}-\mathrm{C}$ becomes more parallel and therefore the signal is enhanced when in laser polarisation direction (Fig. 2E). This example of the effect of orientation reflects again very nicely the high spatial resolution and potential of Raman microscopy. By using the imaging technique layers smaller than $0.5 \mu \mathrm{m}$ (like the S1) can be differentiated, although the extracted spectra might have contribution from the neighbouring regions. Without imaging it would not be possible to gain these spectra, because the laser beam cannot be placed accurately on such a small layer, which is not visible at all in a normal light microscopy image.

\subsection{4. "Modified" cell walls}

Plant fibres and wood are treated in many ways to increase suitability for applications. Raman microscopy has proven to be an important tool in understanding and improving such treatments.

Following mechanical processing of green linseed flax fibres showed clearly an ongoing disappearance of the lignin assigned Raman lines e.g. at $1600 \mathrm{~cm}^{-1}$ (aromatic ring stretch) with increasing number of treatments, indicating that woody parts of the stems were broken and removed [34]. The increasing band sharpness and band intensities of the skeletal modes $\nu_{\mathrm{s}} / \mathrm{as}(\mathrm{C}-\mathrm{O}-\mathrm{C})$ of cellulose at $1096 \mathrm{~cm}^{-1}$ and $1121 \mathrm{~cm}^{-1}$ indicated an increase of cellulose crystallinity by mechanical processing [34]. During $\mathrm{NaOH}$ chemical treatments, so-called mercerization, the polymorphic transformation of cellulose I into cellulose II taking place within the crystalline domains was detected by changes in the $\mathrm{CH}$ stretching vibration as well as stretching modes $\nu_{\mathrm{s}}(\mathrm{C}-\mathrm{O}-\mathrm{C})$ and $\nu_{\text {as }}(\mathrm{C}-\mathrm{O}-\mathrm{C})[78,102]$. Following enzymatic treatment of biomass (Triticum aestivum) with NIR-FT-Raman analysis indicated an increase in crystallinity of the cellulose [103].

In the field of paper making important insights into the understanding of photochemistry and bleaching chemistry of mechanical pulp were gained [104-107]. Furthermore solid wood modification with chemicals, e.g. with fungistatic propiconazole [108], boric acid [109] or Melamin-formaldehyde [110] could be verified with Raman spectroscopy on the cellular level. Besides also natural modification in fossil wood was studied with the help of Raman microscopy [111,112].

\subsubsection{Monitoring molecular stress}

Raman spectroscopy has also been used for evaluating microstructural and molecular changes that occur in samples subjected to stress and strain. Micromechanical studies combined with Raman spectroscopy have been conducted on polymeric fibres $[113,114]$ as well as on various forms of cellulose and wood [115-118] to monitor changes during deformation on the molecular level. The method relies 
on the fact that Raman bands corresponding to the vibrations of structural groups within polymer chain molecules shift towards a lower wavenumber upon tensile deformation of the polymer material [119]. It was shown that during tensile deformation in cellulose fibres and cellulose composite systems (wood and paper) the $1095 \mathrm{~cm}^{-1}$ Raman band, corresponding to the stretching of the cellulose ring structure, shifts towards a lower wavenumber due to molecular deformation $[79,115]$. The magnitude of the wavenumber shift induced by strain and/or stress depends on the molecular structure and microstructure of the sample. Going from testing of wood sections at different strain level [115] to mechanically peeled out single wood fibres and short-time data acquisition during straining allows the investigation of the micromechanics of the cell wall itself [120]. In the single fibre test the failure between attached fibres is excluded and higher stress levels lead to higher band shifts, indicating the real possible straining of the cellulose molecule in the cell wall [120]. Experiments on different cell wall types during deformation will help to deepen the micromechanical understanding of plant cell walls and its macromolecules. This technique can also give important insights into the micromechanics of other biomaterials, e.g. of spider silk [121-123] and of newly created bioinspired composites.

\subsection{Green plant tissue and plant metabolites}

Chlorophyll as a major compound in green plant tissues showed thermal degradation, luminescence and photooxidation when investigated with "classical" Raman spectroscopy and thus limited applications. However, excitation with radiation of $1064 \mathrm{~nm}$ enhances the intensity of the chlorophyll bands by a pre-resonance Raman effect [124] and allows analysis of "green" plants [34].

\subsubsection{Chemotaxonomy}

Spectral changes according to composition give a very distinct fingerprint and enable the use of Raman spectroscopy as a very fast and non-destructive technique for chemotaxonomy. Single needles can be measured and differences due to their chemical composition (mainly terpenes) allow classification of different conifers such as Picea, Pinus, Cedrus, Abies, and Tsuga [15]. Mentha is a taxonomically complex genus, but Raman spectra taken from the glandular trichomes allow the discrimination of taxa by applying cluster analysis [39]. Spectroscopic analysis of essential oils from marjoram and oregano allowed to discriminate between different essential oil profiles from individual oil plants of the same species (chemotypes) [125]. The use of NIR-FT-Raman spectroscopy was furthermore proposed for taxonomical validation of plant germplasm resources gathered in seed collections. This was suggested after successful discrimination of seed spectra among many Apiaceaeous species, including those of similar morphology [126].

\subsubsection{Identification and localization of plant metabolites}

Alkaloids are secondary metabolites of high interest due to their activity against several diseases. Urlaub et al. [127] were able to study in situ the structure and the spatial distribution of naphtylisoquinoline alkaloids in fresh plant material of a tropical liana (Ancistrocladis heyneanus) by micro-FTRaman spectroscopy. Although the chemical structure of the different alkaloids is very similar, the sensitivity of the technique allowed distinguishing ancistroheynine A in the tip of the shoots as well as in the leaf midrib, while the alkaloid ancistrocladine was found to be in the branch root of the plant [14,127]. In another tropical liana (Triphyophyllum peltatum) the antimalaria active naphthylisoquinoline alkaloid dioncophylline A was localized in vivo in $10 \mu \mathrm{m}$ large inclusions located in the bark region of the plant material [128]. Naphthylisoquinoline alkaloids exhibit strong electronic absorptions in the deep-UV spectral range and the Raman excitation wavelengths of 244 and $257 \mathrm{~nm}$ were successfully applied to resonantly enhance the Raman signals of selective vibrations of dioncophylline A 
in situ in different parts (e.g. roots) of T. peltatum [129]. The main alkaloids of poppy (Papaver somniferum L.) were semi-quantitatively determined in capsules, milk and ethanolic extracts by FT-Raman spectroscopy [130]. A very recent study showed in situ flavonoid analysis in dried, green rooibos (Aspalanthus linearis) [131]. Characteristic key bands of aspalathin, the main flavonoid and antioxidant occurring in rooibos, were identified and Raman mapping revealed the spatial distribution within the intact dried leaves [131].

Essential oils of herbs are widely known for their therapeutic effects and medical applications. NIRFT-Raman spectroscopy can give important insight in characterisation and evaluation of the oils itself and the oil plants [132-135]. Raman and surface-enhanced Raman spectroscopic investigations of the essential oil of thyme and oregano showed that they consist of the same monoterpenes, but differ in their quantitative distribution [136]. In different basil chemotypes identification and quantification of valuable as well as carcinogenic substances was possible in the isolated essential oils or solvent extracts, and also in the air-dried herbs [137]. The ability to monitor rapidly various essential oils makes it possible to efficiently select high-quality single plants from wild populations as well as progenies of crossing experiments [135]. Applying Raman mapping allows one to follow the distribution within the plant, e.g. the distribution of essential oils in leaves of different Eucalyptus species [132] or of anethole (one of the main components in the essential oil of fennel), in fruits [138] and seeds [134].

Harpagoside, an iridoid glycosides, that is believed to have a strong antiinflammatory effect, is present in the plant Harpagophytum procumbens in amounts of $0.5-0.6 \%$, and is highly concentrated in the secondary roots. NIR-FT-Raman spectroscopy was used for the identification and quantification in the roots and the spatial distribution was visualized with Raman mapping by using the frequency range from 1618 to $1656 \mathrm{~cm}^{-1}$ including the key signals of harpagoside [139].

Other interesting metabolites studied with NIR-FT-Raman microscopy are carotenoids, which have many important biological functions in plants. Animals and human beings are incapable of carotenoid biosynthesis, but can modify some of them when absorbed from plant food as for example $\beta$-carotene, which can be converted to retinol (vitamin A) [140,141]. In case of carotenoids the detection limit with NIR-FT-Raman technique is drastically increased due to signal enhancement caused by the preresonance effect of the analyte. Spectra obtained from various tissues of a range of plant species indicate that the wavenumber location of $\mathrm{C}=\mathrm{C}$ stretching vibrations is mainly influenced both by the length as well as by the terminal substituents of the polyene chain of carotenoids and by their interaction with other plant constituents. The cis-trans isomerization of carotenoids during processing can be investigated in the intact plant tissue and 2-D Raman mappings show the distribution of individual carotenoids (different 7-, 8-, and 9-double bond conjugated carotenoids) in the sample [142]. Raman mappings with wide increments $(50 \mu \mathrm{m})$ allowed the localisation of carotenoid accumulation in different leaves, tomato fruits and chamomile inflorescence and also changes induced by biotic and abiotic stress $[138,143]$. The main carrot (Daucus carota L.) root carotenoids ( $\alpha$-, $\beta$-carotene, lutein and lycopene) were measured simultaneously in situ in root sections [144]. The Raman mapping technique revealed detailed information regarding the relative content, the distribution, and tissue-specific accumulation of these carotenoids and can supply essential information on carotenogenesis useful for molecular investigations on gene expression and regulation [144]. Some other studies showed promising analysis of polyacetylenes in plants by using NIR-FT-Raman microscopy [145-147]. Besides characterisation and quantification Baranska et al. [147] were able to show structural changes of polyacetylenes in American ginseng roots by a shift of the key band at $2237 \mathrm{~cm}^{-1}$ to about $2258 \mathrm{~cm}^{-1}$ during water loss and rewetting. An explanation of this phenomenon can be due to an interaction of polyacetylene molecules with plant components in the presence of water molecules forming a stable entity that is broken after dehydration. Additionally, the 
results of the simultaneous analysis of different plant constituents, e.g. polysaccharides, polyacetylenes and carotenoids, after applying Raman imaging technique shows their spatial distribution on the same region of interest and thus gives different chemical pictures in context with the structure [148].

The advantage of the high spatial resolution of Raman microscopy furthermore enabled characterisation of accessory compounds in the lumen of single cells, e.g. lipid droplets in the xylem of trees [149] or spherical storage compounds in wood parenchyma cells [63].

\subsubsection{Minerals in plants}

Minerals and inorganic substances in plants are normally determined as the residue remaining after all the combustible material has been burned off (oxidized completely) and subsumed as ash content. Regrettably this method does not result in detailed information about the kind of inorganic. Raman microscopy studies allow the identification, characterisation and spatial localisation of inorganic substances in fossil [111,112,150] and living plants [151-154].

Intracellular inclusions in the pedicel and calyx-tube tissues of Chamelaucium uncinatum were identified as calcium oxalate crystals by Raman spectroscopy [151]. In another study on the cuticula of mango small reddish crystallites containing $\alpha$-quartz and iron oxide $\left(\mathrm{Fe}_{2} \mathrm{O}_{3}\right)$ were identified between wax crystals [152].

The accumulation process of inorganic compounds in animals and plants by biomineralisation is not well understood, though it may be the key to an environmental-compatible production of modern materials in the future. In studies on the silica accumulation in selected Gramineae (Dactylis glomerata L. and Triticum aestivum L.) Raman microscopy was used together with several other methods. Most of the silica was found in cells below the epidermis and in epidermal appendices (bristles, prickle hairs) $[153,154]$.

One of our own recent Raman imaging studies was done on horsetail (Equisetum hyemale), which is known to accumulate high amounts of silica, mostly in the form of amorphous hydrated silica $[155,156]$. On a fresh hand cut cross-section an area scan was done over a region of $200 \mu \mathrm{m} \times 200 \mu \mathrm{m}$. Integrating over the $\mathrm{CH}$-stretching region from 2801 to $3043 \mathrm{~cm}^{-1}$ gives an overall picture of the investigated area, as $\mathrm{CH}$-vibrations derive from almost all organic molecules, including cellulose in the inner and cuticular waxes in the outer region (Fig. 4A). Extracted spectra from the outer appended knobs and the inner part clearly show the different chemical composition (Fig. 5). The broad "band" between 245 and $570 \mathrm{~cm}^{-1}$ is assigned to amorphous silica [157] and shows higher intensity in the spectrum extracted from the knob region (grey line, Fig. 5). Integrating over this band enables the amorphous silica distribution to be followed within the sample (Fig. 4C), confirming that the amorphous silica is mainly accumulated in the outer part and especially in the knobs. To investigate an intact knob in detail a depth scan was performed directly on the intact surface of a thin tangential cut from the outer part of the stem. This was done by scanning a $60 \mu \mathrm{m}$ long line across a knob followed by lines moving always $1 \mu \mathrm{m}$ deeper until a depth of $60 \mu \mathrm{m}$. The $\mathrm{CH}$-stretching image of the depth profiling shows a small layer covering the knob, which represents cuticular waxes (Fig. 5B). By integrating over the amorphous silica band the highest intensity is observed immediately below the cuticular wax layer (Fig. 5D). While the amount of the amorphous silica decreases continuously through the knob (Fig. 5D), the organic contributions show a border and an increase in the opposite direction (Fig. 5B). A detailed analysis of the data will give information about the distribution and also possible differences in the structure of the silica within horsetail (paper in preparation). 

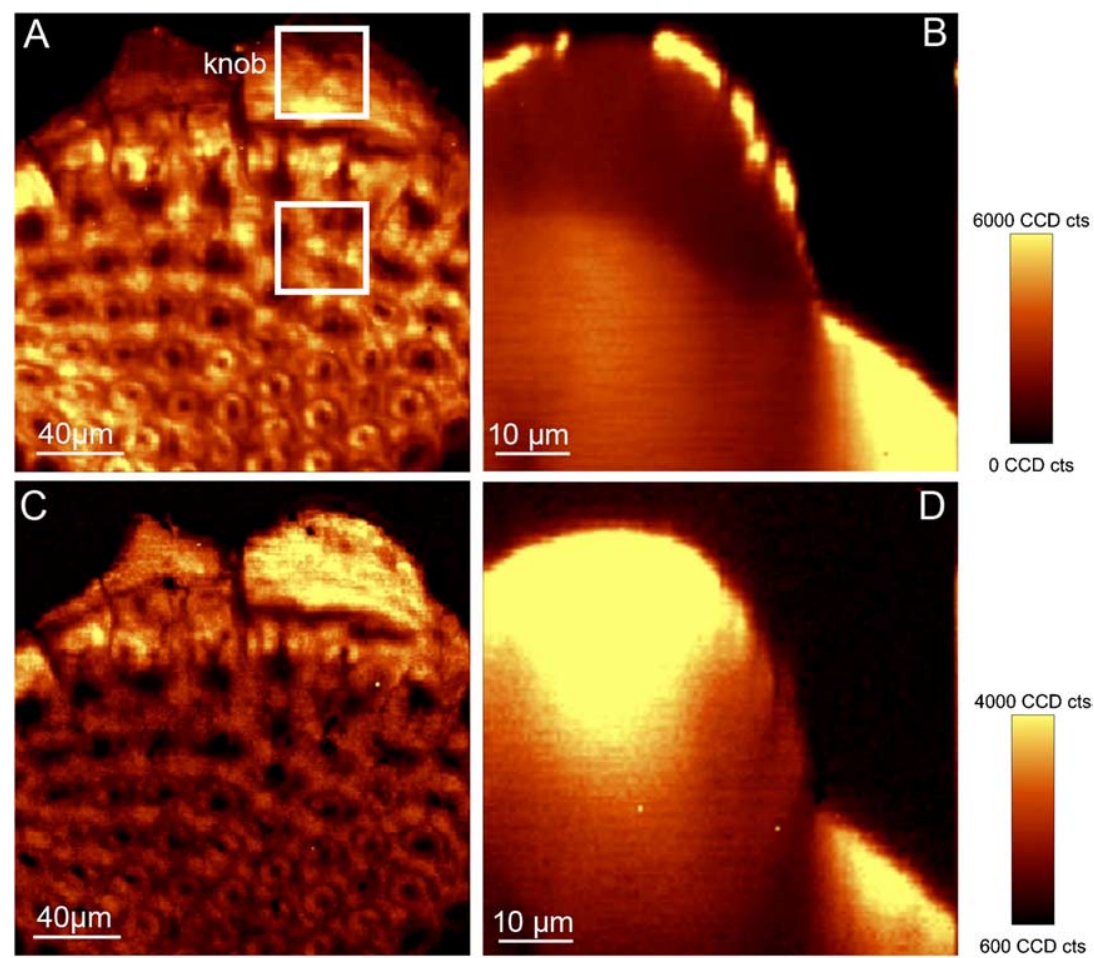

Fig. 4. (A-D) Raman images of an area scan $(200 \mu \mathrm{m} \times 200 \mu \mathrm{m})$ from a cross-section (A, C) and of a depth scan $(60 \mu \mathrm{m} \times 60 \mu \mathrm{m})$ through a knob from the outer surface of a tangential cut (B, D) of Equisetum hyemale. Integration from $2801-3043 \mathrm{~cm}^{-1}$ illustrates the intensity of the $\mathrm{CH}$-stretching vibration and corresponds to the amount of organic material (A, B), whereas integration from 245 to $570 \mathrm{~cm}^{-1}$ images the distribution of amorphous silica (C, D).

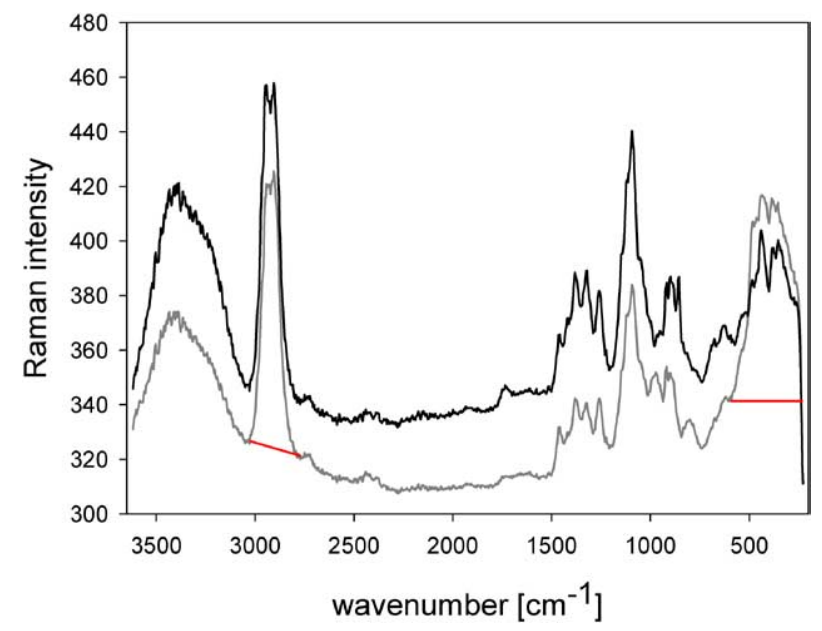

Fig. 5. Raman spectra acquired during an area scan of the cross-section of Equisetum hyemale averaged within the knob (grey line) and inner region (black line) as marked in Fig. 4A (white rectangles). The integration ranges used for the Raman images (Fig. 4) are indicated by lines. 


\section{Conclusions}

Raman microscopic applications on plants are very far ranging, going from investigations on structural polymers to metabolites to mineral substances. Chemical and structural information can be gained in the native state without any staining and complicated sample preparation. The introduction of the NIRFT Raman technique led to many applications on green plant material by eliminating the problem of sample fluorescence. While for mapping and imaging whole plant organs (seeds, fruits, leaves) the lateral resolution with the NIR-FT technique is adequate, investigations on the lower hierarchical level of cells and cell walls need the high resolution gained with a visible laser based system. The chemical imaging studies on wood cell walls illustrate the great potential in revealing changes in chemistry and orientation with a high spatial resolution $(<1 \mu \mathrm{m})$. In addition to the calculation of the chemical images, showing the intensity distribution of various functional groups attributed to the cell wall polymers, underlying spectra can be extracted from very defined regions and assist in data analysis and give additional insights.

\section{Acknowledgements}

We thank R. Nöske (Potsdam University, Department of Chemistry) for providing the horsetail sample, L. Sapei (Max Planck Institute of Colloids and Interfaces, Department Biomaterials, Potsdam) for technical help and I. Burgert, O. Paris and P. Fratzl (Max Planck Institute of Colloids and Interfaces, Department Biomaterials, Potsdam) for enabling the work. J. Dunlop is thanked for reading the manuscript and the valuable comments. The first author (N.G.) was financed during the writing of this review by the APART programme of the Austrian Academy of Sciences.

\section{References}

[1] B. Schrader, Infrared and Raman Spectroscopy, VCH, Weinheim, 1995.

[2] E. Smith and G. Dent, Modern Raman Spectroscopy - A Practical Approach, John Wiley \& Sons Ltd., 2005.

[3] H. Schulz and M. Baranska, Identification and quantification of valuable plant substances by IR and Raman spectroscopy, Vib. Spectrosc. 43 (2007), 13-25.

[4] M. Schmitt and J. Popp, Raman spectroscopy at the beginning of the twenty-first century, J. Raman Spectrosc. 37(1-3) (2006), 20-28.

[5] P.V. Huong, New possibilities of Raman micro-spectroscopy, Vib. Spectrosc. 11(1) (1996), 17-28.

[6] G. Turrell and J. Corset, Raman Microscopy: Developments and Applications, Academic Press, London, 1996.

[7] P. Vandenabeele, Raman spectroscopy in art and archaeology, J. Raman Spectrosc. 35(8-9) (2004), 607-609.

[8] L.G. Thygesen, M.M. Løkkey, E. Micklander and S.B. Engelsen, Vibrational microspectroscopy of food: Raman vs. FT-IR, Trends Food Sci. Technol. 14 (2003), 50-57.

[9] P.D.A. Pudney, T.M. Hancewicz and D.G. Cunningham, The use of confocal Raman spectroscopy to characterise the microstructure of complex biomaterials: foods, Spectr. - Int. J. 16(3-4) (2002), 217-225.

[10] B. Schrader, H. Schulz, G.N. Andreev, H.H. Klump and J. Sawatzki, Non-destructive NIR-FT-Raman spectroscopy of plant and animal tissues, of food and works of art, Talanta $\mathbf{5 3}$ (2000), 35-45.

[11] C.-Y. Ma and D.L. Phillips, FT-Raman spectroscopy and its applications in cereal science, Cereal Chem. 79(2) (2002), 171-177.

[12] K. Gaus, P. Rosch, R. Petry, K.D. Peschke, O. Ronneberger, H. Burkhardt, K. Baumann and J. Popp, Classification of lactic acid bacteria with UV-resonance Raman spectroscopy, Biopolymers 82(4) (2006), 286-290.

[13] D. Chenery and H. Bowring, Infrared and Raman spectroscopic imaging in bioscience, Spectroscopy Europe 15(4) (2003), 8-14.

[14] R. Petry, M. Schmitt and J. Popp, Raman spectroscopy - A prospective tool in the life sciences, Chem. Phys. Chem. 4(1) (2003), 14-30.

[15] B. Schrader, B. Dippel, I. Erb, S. Keller, T. Löchte, H. Schulz, E. Tatsch and S. Wessel, NIR Raman spectroscopy in medicine and biology: results and aspect, J. Mol. Struct. 480-481 (1999), 21-32. 
[16] P. Rösch, M. Harz, K.D. Peschke, O. Ronneberger, H. Burkhardt and J. Popp, Identification of single eukaryotic cells with micro-Raman spectroscopy, Biopolymers 82(4) (2006), 312-316.

[17] P. Rösch, M. Harz, M. Schmitt and J. Popp, Raman spectroscopic identification of single yeast cells, J. Raman Spectrosc. 36(5) (2005), 377-379.

[18] S. Keller, B. Schrader, A. Hoffmann, W. Schrader, K. Metz, A. Rehlaender, J. Pahnke, M. Ruwe and W. Budach, Application of near-Infrared Fourier-Transform Raman-spectroscopy in medical-research, J. Raman Spectrosc. 25(7-8) (1994), 663-671.

[19] R. Mendelsohn, C.R. Flach and D.J. Moore, Determination of molecular conformation and permeation in skin via IR spectroscopy, microscopy, and imaging, Biochim. Biophys. Acta - Biomembr. 1758(7) (2006), 923-933.

[20] C. Otto, C.J. de Grauw, J.J. Duindam, N.M. Sijtsema and J. Greve, Applications of micro-Raman imaging in biomedical research, J. Raman Spectrosc. 28 (1997), 143-150.

[21] C.A. Owen, J. Selvakumaran, I. Notingher, G. Jell, L.L. Hench and M.M. Stevens, In vitro toxicology evaluation of pharmaceuticals using Raman micro-spectroscopy, J. Cell. Biochem. 99 (2006), 178-186.

[22] S.C. Pinzaru, I. Pavel, N. Leopold and W. Kiefer, Identification and characterization of pharmaceuticals using Raman and surface-enhanced Raman scattering, J. Raman Spectrosc. 35(5) (2004), 338-346.

[23] G. Pezzotti, Raman piezo-spectroscopic analysis of natural and synthetic biomaterials, Anal. Bioanal. Chem. 381(3) (2005), 577-590.

[24] H.G.M. Edwards and T. Munshi, Diagnostic Raman spectroscopy for the forensic detection of biomaterials and the preservation of cultural heritage, Anal. Bioanal. Chem. 382(6) (2005), 1398-1406.

[25] M.R. Murphy, K.M. Faucher, X.L. Sun, E.L. Chaikof and R.A. Dluhy, Analysis of photoinitiated polymerization in a membrane mimetic film using infrared spectroscopy and near-IR Raman microscopy, Colloid Surf. B - Biointerfaces 46(4) (2005), 226-232.

[26] S.A. Redey, M. Nardin, D. Bernache-Assolant, C. Rey, P. Delannoy, L. Sedel and P.J. Marie, Behavior of human osteoblastic cells on stoichiometric hydroxyapatite and type A carbonate apatite: Role of surface energy, Journal of Biomedical Materials Research 50(3) (2000), 353-364.

[27] M. Delhaye and P. Dhamelincourt, Raman microprobe and microscope with laser excitation, Journal of Raman Spectroscopy 3(1) (1975), 33-43.

[28] S. Bradbury, An introduction to the Optical Microscope, Oxford University Press, New York, 1989.

[29] U.P. Agarwal, An overview of Raman Spectroscopy as applied to lignocellulosic materials, in: Advances in Lignocellulosics Characterization, D.S. Argyropoulos, ed., TAPPI Press, Atlanta, GA, 1999, pp. 209-225.

[30] R.L. McCreery, Raman Spectroscopy for Chemical Analysis, Wiley-Interscience, New York, 2000.

[31] T. Hirschfeld and B. Chase, Ft-Raman spectroscopy - development and justification, Applied Spectroscopy 40(2) (1986), 133-137.

[32] B. Schrader, Raman spectroscopy in the near infrared - A most capable method of vibrational spectroscopy, Fresenius J. Anal. Chem. 355(3-4) (1996), 233-239.

[33] B. Schrader, A. Hoffmann, A. Simon and J. Sawatzki, Can a Raman renaissance be expected via the near-Infrared Fourier-Transform technique, Vib. Spectrosc. 1(3) (1991), 239-250.

[34] B. Schrader, H.H. Klump, K. Schenzel and H. Schulz, Non-destructive NIR FT Raman analysis of plants, J. Mol. Struct. 509 (1999), 201-212.

[35] B. Schrader, A. Hoffmann and S. Keller, Near-Infrared Fourier-Transform Raman-spectroscopy - Facing absorption and background, Spectroc. Acta Pt. A - Molec. Biomolec. Spectr. 47(9-10) (1991), 1135-1148.

[36] S.F. Parker, A review of the theory of Fourier-transform Raman spectroscopy, Spectroc. Acta Pt. A - Molec. Biomolec. Spectr. 50A(11) (1994), 1841-1856.

[37] P. Hildebrandt, S. Keller, A. Hoffmann, F. Vanhecke and B. Schrader, Enhancement factor of surface-enhanced Ramanscattering on silver and gold surfaces upon near-Infrared excitation - Indication of an unusual strong contribution of the chemical effect, J. Raman Spectrosc. 24(11) (1993), 791-796.

[38] R. Gessner, P. Rösch, R. Petry, M. Schmitt, M.A. Strehle, W. Kiefer and J. Popp, The application of a SERS fiber probe for the investigation of sensitive biological samples, Analyst 129(12) (2004), 1193-1199.

[39] R. Gessner, P. Rösch, W. Kiefer and J. Popp, Raman spectroscopy investigation of biological materials by use of etched and silver coated glass fiber tips, Biopolymers 67(4-5) (2002), 327-330.

[40] R.F. Aroca and C.J.L. Constantino, Surface-enhanced Raman scattering: Imaging and mapping of Langmuir-Blodgett monolayers physically adsorbed onto silver island films, Langmuir 16(12) (2000), 5425-5429.

[41] C.J.L. Constantino, J. Duff and R. Aroca, Surface enhanced resonance Raman scattering imaging of Langmuir-Blodgett monolayers of bis (benzimidazo) thioperylene, Spectrochim. Acta A 57(6) (2001), 1249-1259.

[42] V.V. Yakovlev, Advanced instrumentation for non-linear Raman microscopy, J. Raman Spectrosc. 34 (2003), 957-964.

[43] J.-X. Cheng, L.D. Book and X.S. Xie, Polarization coherent anti-Stokes Raman scattering microscopy, Opt. Lett. 26(17) (2000), 1341-1343. 
[44] J.X. Cheng and X.S. Xie, Coherent anti-Stokes Raman scattering microscopy: Instrumentation, theory, and applications, J. Phys. Chem. B 108(3) (2004), 827-840.

[45] L.G. Rodriguez, S.J. Lockett and G.R. Holtom, Coherent anti-stokes Raman scattering microscopy: A biological review, Cytom. Part A 69A(8) (2006), 779-791.

[46] A. Volkmer, Vibrational imaging and microspectroscopies based on coherent anti-Stokes Raman scattering microscopy, J. Phys. D - Appl. Phys. 38(5) (2005), R59-R81.

[47] D.B. Chase, Fourier-Transform Raman-Spectroscopy, J. Am. Chem. Soc. 108(24) (1986), 7485-7488.

[48] W.D. Bowman and T.G. Spiro, Fluorescence-free resonance raman-spectra of reduced nicotinamide adenine-dinucleotide via ultraviolet excitation, J. Raman Spectrosc. 9(6) (1980), 369-371.

[49] H.S. Sands, I.P. Hayward, T.E. Kirkbride, R. Bennett, R.J. Lacey and D.N. Batchelder, UV-excited resonance Raman spectroscopy of narcotics and explosives, J. Forensic. Sci. 43(3) (1998), 509-513.

[50] P. Matousek, M. Towrie and A.W. Parker, Fluorescence background suppression in Raman spectroscopy using combined Kerr gated and shifted excitation Raman difference techniques, J. Raman Spectrosc. 33(4) (2002), 238-242.

[51] A.P. Shreve, N.J. Cherepy and R.A. Mathies, Effective rejection of fluorescence interference in Raman-spectroscopy using a shifted excitation difference technique, Appl. Spectrosc. 46(4) (1992), 707-711.

[52] S.M. Angel, M.K. Dearmond, R.J. Donohoe, K.W. Hanck and D.W. Wertz, Resonance Raman-spectra of the 1st 3 reduction products of Tris(Bipyridyl)Ruthenium(Ii), J. Am. Chem. Soc. 106(12) (1984), 3688-3689.

[53] P.A. Mosier-Boss, S.H. Lieberman and R. Newbery, Fluorescence rejection in Raman-spectroscopy by shifted-spectra, edge-detection, and FFT filtering techniques, Appl. Spectrosc. 49(5) (1995), 630-638.

[54] J.M. Harris, R.W. Chrisman, F.E. Lytle and R.S. Tobias, Sub-nanosecond time-resolved rejection of fluorescence from Raman-spectra, Anal. Chem. 48(13) (1976), 1937-1943.

[55] T. Tahara and H.O. Hamaguchi, Picosecond Raman-spectroscopy using a streak camera, Appl. Spectrosc. 47(4) (1993), 391-398.

[56] N. Everall, T. Hahn, P. Matousek, A.W. Parker and M. Towrie, Picosecond time-resolved Raman spectroscopy of solids: Capabilities and limitations for fluorescence rejection and the influence of diffuse reflectance, Appl. Spectrosc. 55(12) (2001), 1701-1708.

[57] P. Matousek, M. Towrie, C. Ma, W.M. Kwok, D. Phillips, W.T. Toner and A.W. Parker, Fluorescence suppression in resonance Raman spectroscopy using a high-performance picosecond Kerr gate, J. Raman Spectrosc. 32(12) (2001), 983-988.

[58] P. Matousek, M. Towrie, A. Stanley and A.W. Parker, Efficient rejection of fluorescence from Raman spectra using picosecond Kerr gating, Appl. Spectrosc. 53(12) (1999), 1485-1489.

[59] R. Picorel, G. Chumanov, E. Torrado, T.M. Cotton and M. Seibert, Surface-enhanced resonance Raman scattering spectroscopy of plant photosystem II reaction centers excited on the red-edge of the Q(y) band, J. Phys. Chem. B 102(15) (1998), 2609-2613.

[60] R. Picorel, M. Bakhtiari, T. Lu, T.M. Cotton and M. Seibert, Surface-Enhanced Resonance Raman-Scattering Spectroscopy as a Surface-Topography Probe in Plant Photosynthetic Membranes, Photochem. Photobiol. 56(2) (1992), 263270.

[61] M.D. Schaeberle, H.R. Morris, J.F. Turner and P.J. Treado, Raman chemical imaging spectroscopy, Anal. Chem. 71(5) (1999), 175a-181a.

[62] J. Barbillat, Raman imaging, Raman microscopy?

[63] N. Gierlinger and M. Schwanninger, Chemical imaging of poplar wood cell walls by confocal Raman microscopy, Plant Physiol. 140(4) (2006), 1246-1254.

[64] U.P. Agarwal, Raman imaging to investigate ultrastructure and composition of plant cell walls: distribution of lignin and cellulose in black spruce wood (Picea mariana), Planta 224(5) (2006), 1141-1153.

[65] J.J. Andrew and T.M. Hancewicz, Rapid analysis of raman image data using two-way multivariate curve resolution, Appl. Spectrosc. 52(6) (1998), 797-807.

[66] N.J. Everall, Confocal Raman microscopy: Why the depth resolution and spatial accuracy can be much worse than you think, Appl. Spectrosc. 54(10) (2000), 1515-1520.

[67] N.J. Everall, Modeling and measuring the effect of refraction on the depth resolution of confocal Raman microscopy, Appl. Spectrosc. 54(6) (2000), 773-782.

[68] N. Gierlinger and I. Burgert, Secondary cell wall polymers studied by Confocal Raman microscopy: Spatial distribution, orientation and molecular deformation, New Zealand Journal of Forestry Science 36(1) (2006), 60-71.

[69] M.C. Jarvis and M.C. McCann, Macromolecular biophysics of the plant cell wall: Concepts and methodology, Plant Physiol. Biochem. 38(1-2) (2000), 1-13.

[70] C.F.B. Séné, M.C. McCann, R.H. Wilson and R. Crinter, Fourier-Transform Raman and Fourier-Transform lnfrared spectroscopy. An investigation of five higher plant cell walls and their components, Plant Physiol. 106 (1994), 16231631. 
[71] R.H. Atalla, J. Ranua and E.W. Malcolm, Raman-spectroscopic studies of the structure of cellulose - a comparison of Kraft and sulfite pulps, TAPPI J. 67(2) (1984), 96-99.

[72] J.H. Wiley and R.H. Atalla, Band assignments in the Raman-spectra of celluloses, Carbohydr. Res. 160 (1987), 113-129.

[73] R.H. Atalla, R.E. Whitmore and C.J. Heimbach, Raman spectral evidence for molecular-orientation in native cellulosic fibers, Macromolecules 13(6) (1980), 1717-1719.

[74] D. Klemm, B. Heublein, H.P. Fink and A. Bohn, Cellulose: Fascinating biopolymer and sustainable raw material, Angew. Chem. Int. Edit. 44(22) (2005), 3358-3393.

[75] S. Fischer, K. Schenzel, K. Fischer and W. Diepenbrock, Applications of FT Raman spectroscopy and micro spectroscopy characterizing cellulose and cellulosic biomaterials, Macromolecular Symposia 223 (2005), 41-56.

[76] D.S. Himmelsbach, S. Khahili and D.E. Akin, Near-infrared-Fourier-transform-Raman microspectroscopic imaging of flax stems, Vib. Spectrosc. 19 (1999), 361-367.

[77] H.G.M. Edwards, D.W. Farwell and D. Webster, FT Raman microscopy of untreated natural plant fibres, Spectroc. Acta Pt. A - Molec. Biomolec. Spectr. 53(13) (1997), 2383-2392.

[78] A. Jähn, M.W. Schröder, M. Füting, K. Schenzel and W. Diepenbrock, Characterization of alkali treated flax fibres by means of FT Raman spectroscopy and environmental scanning electron microscopy, Spectroc. Acta Pt. A - Molec. Biomolec. Spectr. 58 (2002), 2271-2279.

[79] P. Peetla, K.C. Schenzel and W. Diepenbrock, Determination of mechanical strength properties of hemp fibers using near-infrared Fourier transform Raman microspectroscopy, Appl. Spectrosc. 60(6) (2006), 682-691.

[80] W.H. Morrison, D.S. Himmelsbach, D.E. Akin and J.D. Evans, Chemical and spectroscopic analysis of lignin in isolated flax fibers, J. Agric. Food Chem. 51(9) (2003), 2565-2568.

[81] Y.L. Liu, S. Kokot and T.J. Sambi, Vibrational spectroscopic investigation of Australian cotton cellulose fibres - Part 1. A Fourier transform Raman study, Analyst 123(4) (1998), 633-636.

[82] R.H. Atalla and U.P. Agarwal, Raman microprobe evidence for lignin orientation in the cell walls of native woody tissue, Science 227 (1985), 636-638.

[83] U.P. Agarwal and R.H. Atalla, In situ Raman microprobe studies of plant-cell walls - macromolecular organization and compositional variability in the secondary wall of Picea-Mariana (Mill) Bsp, Planta 169(3) (1986), 325-332.

[84] R.H. Atalla, Raman-spectroscopy and the Raman microprobe - Valuable new tools for characterizing wood and wood pulp fibers, J. Wood Chem. Technol. 7(1) (1987), 115-131.

[85] R.H. Atalla and U.P. Agarwal, Recording Raman-spectra from plant-cell walls, J. Raman Spectrosc. 17(2) (1986), 229231.

[86] C. Plomion, G. Leprovost and A. Stokes, Wood formation in trees, Plant Physiol. 127 (2001), 1513-1523.

[87] D. Fengel and G. Wegener, Wood: Chemistry, Ultrastructure, Reactions, Walter de Gruyter \& Co., Berlin, 1989.

[88] M. Halttunen, J. Vyörykkä, B. Hortling, T. Tamminen, D. Batchelder, A. Zimmermann and T. Vuorinen, Study of residual lignin in pulp by UV Resonance Raman spectroscopy, Holzforschung 55 (2001), 631-638.

[89] A.M. Saariaho, A.S. Jääskeläinen, M. Nuopponen and T. Vuorinen, Ultra violet resonance Raman spectroscopy in lignin analysis: Determination of characteristic vibrations of p-hydroxyphenyl, guaiacyl, and syringyl lignin structures, Appl. Spectrosc. 57(1) (2003), 58-66.

[90] M. Nuopponen, S. Willfor, A. Jääskeläinen, A. Sundberg and T. Vuorinen, A UV resonance Raman (UVRR) spectroscopic study on the extractable compounds of Scots pine (Pinus sylvestris) wood Part I: Lipophilic compounds, Spectroc. Acta Pt. A - Molec. Biomolec. Spectr. 60(13) (2004), 2953-2961.

[91] A.M. Saariaho, D.S. Argyropoulos, A.S. Jääskeläinen and T. Vuorinen, Development of the partial least squares models for the interpretation of the UV resonance Raman spectra of lignin model compounds, Vib. Spectrosc. 37(1) (2005), $111-121$.

[92] A.D. Czaja, A.B. Kudravtsev and W. Schopf, New method for the microscopic, nondestructive acquisition of ultraviolet resonance raman spectra from plant cell walls, Appl. Spectrosc. 60(4) (2006), 352-355.

[93] D. Stewart, N. Yahiaoui, G.J. McDougall, K. Myton, C. Marque, A.M. Boudet and J. Haigh, Fourier-transform infrared and Raman spectroscopic evidence for the incorporation of cinnamaldehydes into the lignin of transgenic tobacco (Nicotiana tabacum L) plants with reduced expression of cinnamyl alcohol dehydrogenase, Planta 201(3) (1997), 311-318.

[94] U.P. Agarwal and S.A. Ralph, FT-Raman spectroscopy of wood: Identifying contributions of lignin and carbohydrate polymers in the spectrum of black spruce (Picea mariana), Appl. Spectrosc. 51(11) (1997), 1648-1655.

[95] S. Barsberg, P. Matousek, M. Towrie, H. Jorgensen and C. Felby, Lignin radicals in the plant cell wall probed by Kerrgated resonance Raman spectroscopy, Biophys. J. 90(8) (2006), 2978-2986.

[96] A.M. Saariaho, A.S. Jääskeläinen, P. Matousek, M. Towrie, A.W. Parker and T. Vuorinen, Resonance Raman spectroscopy of highly fluorescing lignin containing chemical pulps: Suppression of fluorescence with an optical Kerr gate, Holzforschung 58(1) (2004), 82-90.

[97] V.C. Tirumalai, U.P. Agarwal and J.R. Obst, Heterogeneity of lignin concentration in cell corner middle lamella of white birch and black spruce, Wood Sci. Technol. 30(2) (1996), 99-104.

[98] T. Röder, G. Koch and H. Sixta, Application of confocal Raman spectroscopy for the topochemical distribution of lignin 
and cellulose in plant cell walls of beech wood (Fagus sylvatica L.) compared to UV microspectrophotometry, Holzforschung 58(5) (2004), 480-482.

[99] M. Tanaka and R.J. Young, Polarised Raman spectroscopy for the study of molecular orientation distributions in polymers, J. Mater. Sci. 41(3) (2006), 963-991.

[100] U.P. Agarwal and R.H. Atalla, In situ Raman microprobe studies of plant-cell walls - macromolecular organization and compositional variability in the secondary wall of Picea mariana (Mill) Bsp, Planta 169(3) (1986), 325-332.

[101] Y. Cao, D.Y. Shen, Y.L. Lu and Y. Huang, A Raman-scattering study on the net orientation of biomacromolecules in the outer epidermal walls of mature wheat stems (Triticum aestivum), Ann. Bot. 97(6) (2006), 1091-1094.

[102] K. Schenzel and S. Fischer, NIR FT Raman spectroscopy - a rapid analytical tool for detecting the transformation of cellulose polymorphs, Cellulose $\mathbf{8}$ (2001), 49-57.

[103] Y. Cao, Y.L. Lu and Y. Huang, NIR FT-Raman study of biomass (Triticum aestivum) treated with cellulase, J. Mol. Struct. 693(1-3) (2004), 87-93.

[104] U.P. Agarwal and L.L. Landucci, FT-Raman investigation of bleaching of spruce thermornechanical pulp, J. Pulp Pap. Sci. 30(10) (2004), 269-274.

[105] U.P. Agarwal, Assignment of the photoyellowing-related $1675 \mathrm{~cm}^{-1}$ Raman/IR band to p-quinones and its implications to the mechanism of color reversion in mechanical pulps, J. Wood Chem. Technol. 18(4) (1998), 381-402.

[106] U.P. Agarwal and R.H. Atalla, Raman spectral features associated with chromophores in high-yield pulps, J. Wood Chem. Technol. 14(2) (1994), 227-241.

[107] I.A. Weinstock, R.H. Atalla, U.P. Agarwal, J.L. Minor and C. Petty, Fourier-Transform Raman-spectroscopic studies of a novel wood pulp bleaching system, Spectroc. Acta Pt. A - Molec. Biomolec. Spectr. 49(5-6) (1993), 819-829.

[108] E. Kurti, D.V. Heyd and R.S. Wylie, Raman microscopy for the quantitation of propiconazole in white spruce, Wood Sci. Technol. 39(8) (2005), 618-629.

[109] S. Yamauchi and S. Doi, Raman spectroscopic study on the behavior of boric acid in wood, J. Wood Sci. 49(3) (2003), 227-234.

[110] N. Gierlinger, C. Hansmann, T. Röder, H. Sixta, W. Gindl and R. Wimmer, Comparison of UV and confocal Raman microscopy to measure the melamine-formaldehyde resin content within cell walls of impregnated spruce wood, Holzforschung 59(2) (2005), 210-213.

[111] K. Witke, J. Gotze, R. Rossler, D. Dietrich and G. Marx, Raman and cathodoluminescence spectroscopic investigations on Permian fossil wood from Chemnitz - a contribution to the study of the permineralisation process, Spectroc. Acta Pt. A-Molec. Biomolec. Spectr. 60(12) (2004), 2903-2912.

[112] J. Nowak, M. Florek, W. Kwiatek, J. Lekki, P. Chevallier, E. Zieba, N. Mestres, E.M. Dutkiewicz and A. Kuczumow, Composite structure of wood cells in petrified wood, Mater. Sci. Eng. C-Biomimetic Supramol. Syst. 25(2) (2005), 119-130.

[113] R.J. Davies, S.J. Eichhorn, C. Riekel and R.J. Young, Crystal lattice deformation in single poly(p-phenylene benzobisoxazole) fibres, Polymer 45(22) (2004), 7693-7704.

[114] W.-Y. Yeh and R.J. Young, Molecular deformation processes in aromatic high modulus polymer fibres, Polymer 40 (1999), 857-870.

[115] S.J. Eichhorn, J. Sirichaisit and R.J. Young, Deformation mechanisms in cellulose fibres, paper and wood, Journal of Material Science 36 (2001), 3129-3135.

[116] S.J. Eichhorn, R.J. Young, R.J. Davies and C. Riekel, Characterisation of the microstructure and deformation of high modulus cellulose fibres, Polymer 44(19) (2003), 5901-5908.

[117] A. Sturcova, G.R. Davies and S.J. Eichhorn, Elastic modulus and stress-transfer properties of tunicate cellulose whiskers, Biomacromolecules 6(2) (2005), 1055-1061.

[118] K. Kong and S.J. Eichhorn, Crystalline and amorphous deformation of process-controlled cellulose-II fibres, Polymer 46(17) (2005), 6380-6390.

[119] D.N. Batchelder and D. Bloor, Strain dependence of the vibrational modes of a diacetylene crystal, J. Polym. Sci. Pol. Phys. 17(4) (1979), 569-581.

[120] N. Gierlinger, M. Schwanninger, A. Reinecke and I. Burgert, Molecular changes during tensile deformation of single wood fibers followed by Raman microscopy, Biomacromolecules 7(7) (2006), 2077-2081.

[121] Y. Noishiki, Y. Nishiyama, M. Wada, S. Kuga and J. Magoshi, Mechanical properties of silk fibroin-microcrystalline cellulose composite films, J. Appl. Polym. Sci. 86(13) (2002), 3425-3429.

[122] M.E. Rousseau, T. Lefevre, L. Beaulieu, T. Asakura and M. Pezolet, Study of protein conformation and orientation in silkworm and spider silk fibers using Raman microspectroscopy, Biomacromolecules 5(6) (2004), 2247-2257.

[123] Z.J. Pan, C.P. Li and Q. Xu, Active control on molecular conformations and tensile properties of spider silk, J. Appl. Polym. Sci. 92(2) (2004), 901-905.

[124] T.A. Mattioli, A. Hoffmann, M. Lutz and B. Schrader, Fourier-Transform Qy Preresonance Raman-Spectroscopy of Bacteriochlorophyll-A, Cr. Acad. Sci. Iii-Vie 310(10) (1990), 441-446. 
[125] M. Baranska, H. Schulz, H. Kruger and R. Quilitzsch, Chemotaxonomy of aromatic plants of the genus Origanum via vibrational spectroscopy, Anal. Bioanal. Chem. 381(6) (2005), 1241-1247.

[126] R. Baranski, M. Baranska, H. Schulz, P.W. Simon and T. Nothnagel, Single seed Raman measurements allow taxonomical discrimination of Apiaceae accessions collected in gene banks, Biopolymers 81(6) (2006), 497-505.

[127] E. Urlaub, J. Popp, W. Kiefer, G. Bringmann, D. Koppler, H. Schneider, U. Zimmermann and B. Schrader, FT-Raman investigation of alkaloids in the liana Ancistrocladus heyneanus, Biospectroscopy 4(2) (1998), 113-120.

[128] T. Frosch, M. Schmitt, K. Schenzel, J.H. Faber, G. Bringmann, W. Kiefer and J. Popp, In vivo localization and identification of the antiplasmodial alkaloid dioncophylline A in the tropical liana Triphyophyllum peltatum by a combination of fluorescence, near infrared Fourier transform Raman microscopy, and density functional theory calculations, Biopolymers 82(4) (2006), 295-300.

[129] T. Frosch, M. Schmitt, T. Noll, G. Bringmann, K. Schenzel and J. Popp, Ultrasensitive in situ tracing of the alkaloid dioncophylline A in the tropical liana Triphyophyllum peltatum by applying deep-UV Resonance Raman microscopy, Anal. Chem. doi:10.1021/ac061526q (2006).

[130] H. Schulz, M. Baranska, R. Quilitzsch and W. Schutze, Determination of alkaloids in capsules, milk and ethanolic extracts of poppy (Papaver somniferum L.) by ATR-FT-IR and FT-Raman spectroscopy, Analyst 129(10) (2004), 917920.

[131] M. Baranska, H. Schulz, E. Joubert and M. Manley, In situ flavonoid analysis by FT-Raman spectroscopy: Identification, distribution, and quantification of aspalathin in green rooibos (Aspalathus linearis), Anal. Chem. 78(22) (2006), 77167721.

[132] M. Baranska, H. Schulz, S. Reitzenstein, U. Uhlemann, M.A. Strehle, H. Kruger, R. Quilitzsch, W. Foley and J. Popp, Vibrational spectroscopic studies to acquire a quality control method of Eucalyptus essential oils, Biopolymers 78(5) (2005), 237-248.

[133] H. Schulz, G. Ozkan, M. Baranska, H. Kruger and M. Ozcan, Characterisation of essential oil plants from Turkey by IR and Raman spectroscopy, Vib. Spectrosc. 39(2) (2005), 249-256.

[134] M.A. Strehle, P. Rösch, M. Baranska, H. Schulz and J. Popp, On the way to a quality control of the essential oil of fennel by means of Raman spectroscopy, Biopolymers 77(1) (2005), 44-52.

[135] H. Schulz, M. Baranska, H.H. Belz, P. Rösch, M.A. Strehle and J. Popp, Chemotaxonomic characterisation of essential oil plants by vibrational spectroscopy measurements, Vib. Spectrosc. 35(1-2) (2004), 81-86.

[136] P. Rösch, J. Popp and W. Kiefer, Raman and surface enhanced Raman spectroscopic investigation on Lamiaceae plants, J. Mol. Struct. 481 (1999), 121-124.

[137] H. Schulz, B. Schrader, R. Quilitzsch, S. Pfeffer and H. Kruger, Rapid classification of basil chemotypes by various vibrational spectroscopy methods, J. Agric. Food Chem. 51(9) (2003), 2475-2481.

[138] M. Baranska, H. Schulz, P. Rosch, M.A. Strehle and J. Popp, Identification of secondary metabolites in medicinal and spice plants by NIR-FT-Raman microspectroscopic mapping, Analyst 129(10) (2004), 926-930.

[139] M. Baranska, H. Schulz, R. Siuda, M.A. Strehle, P. Rosch, J. Popp, E. Joubert and M. Manley, Quality control of Harpagophytum procumbens and its related phytopharmaceutical products by means of NIR-FT-Raman spectroscopy, Biopolymers 77(1) (2005), 1-8.

[140] J.A. Olson, Provitamin-A function of carotenoids - the conversion of beta-carotene into vitamin-A, J. Nutr. 119(1) (1989), 105-108.

[141] J.A. Olson, Vitamin-A and carotenoids as antioxidants in a physiological context, J. Nutr. Sci. Vitaminol. 39 (1993), S57-S65.

[142] H. Schulz, M. Baranska and R. Baranski, Potential of NIR-FT-Raman spectroscopy in natural carotenoid analysis, Biopolymers 77(4) (2005), 212-221.

[143] R. Baranski, M. Baranska and H. Schulz, Changes in carotenoid content and distribution in living plant tissue can be observed and mapped in situ using NIR-FT-Raman spectroscopy, Planta 222(3) (2005), 448-457.

[144] M. Baranska, R. Baranski, H. Schulz and T. Nothnagel, Tissue-specific accumulation of carotenoids in carrot roots, Planta 224(5) (2006), 1028-1037.

[145] B. Schrader, H. Schulz, M. Baranska, G.N. Andreev, C. Lehner and J. Sawatzki, Non-destructive Raman analyses polyacetylenes in plants, Spectroc. Acta Pt. A - Molec. Biomolec. Spectr. 61(7) (2005), 1395-1401.

[146] M. Baranska and H. Schulz, Spatial tissue distribution of polyacetylenes in carrot root, Analyst 130(6) (2005), 855-859.

[147] M. Baranska, H. Schulz and L.P. Christensen, Structural changes of polyacetylenes in American ginseng root can be observed in situ by using Raman spectroscopy, J. Agric. Food Chem. 54(10) (2006), 3629-3635.

[148] M. Baranska, H. Schulz, R. Baranski, T. Nothnagel and L.P. Christensen, In situ simultaneous analysis of polyacetylenes, carotenoids and polysaccharides in carrot roots, J. Agric. Food Chem. 53(17) (2005), 6565-6571.

[149] P. Rösch, H. Schneider, U. Zimmermann, W. Kiefer and J. Popp, In situ Raman investigation of single lipid droplets in the water-conducting xylem of four woody plant species, Biopolymers 74(1-2) (2004), 151-156.

[150] D. Dietrich, K. Witke, R. Rossler and G. Marx, Raman spectroscopy on Psaronius sp.: a contribution to the understanding of the permineralization process, Appl. Surf. Sci. 179(1-4) (2001), 230-233. 
[151] A.J. Macnish, D.E. Irving, D.C. Joyce, V. Vithanage, A.H. Wearing, R.I. Webb and R.L. Frost, Identification of intracellular calcium oxalate crystals in Chamelaucium uncinatum (Myrtaceae), Aust. J. Bot. 51(5) (2003), 565-572.

[152] L.C. Prinsloo, W. du Plooy and C. van der Merwe, Raman spectroscopic study of the epicuticular wax layer of mature mango (Mangifera indica) fruit, J. Raman Spectrosc. 35(7) (2004), 561-567.

[153] D. Dietrich, S. Hemeltjen, N. Meyer, E. Baucker, G. Ruhle, O. Wienhaus and G. Marx, A new attempt to study biomineralised silica bodies in Dactylis glomerata L., Anal. Bioanal. Chem. 374(4) (2002), 749-752.

[154] D. Dietrich, S. Hinke, W. Baumann, R. Fehlhaber, E. Baucher, G. Ruhle, O. Wienhaus and G. Marx, Silica accumulation in Triticum aestivum L. and Dactylis glomerata L., Anal. Bioanal. Chem. 376(3) (2003), 399-404.

[155] G. Holzhüter, K. Narayanan and T. Gerber, Structure of silica in Equisetum arvense, Anal. Bioanal. Chem. 376(4) (2003), 512-517.

[156] C.C. Perry and T. Keeling-Tucker, Model studies of colloidal silica precipitation using biosilica extracts from Equisetum telmateia, Colloid Polym. Sci. 281(7) (2003), 652-664.

[157] H.S. Chen, S.F. Ji, J.Z. Niu, B.H. Xie and S.B. Li, Vibration spectroscopy on transformation of amorphous silica to alpha-cristobalite, Acta Phys. Chim. Sin. 15(5) (1999), 454-457. 


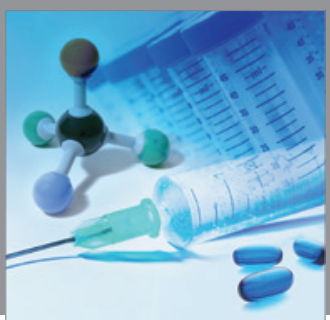

International Journal of

Medicinal Chemistry

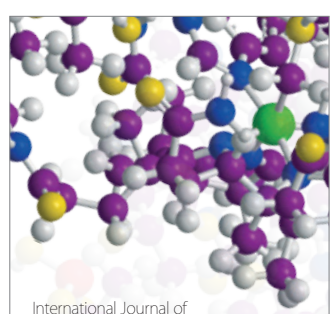

Carbohydrate Chemistry



The Scientific World Journal
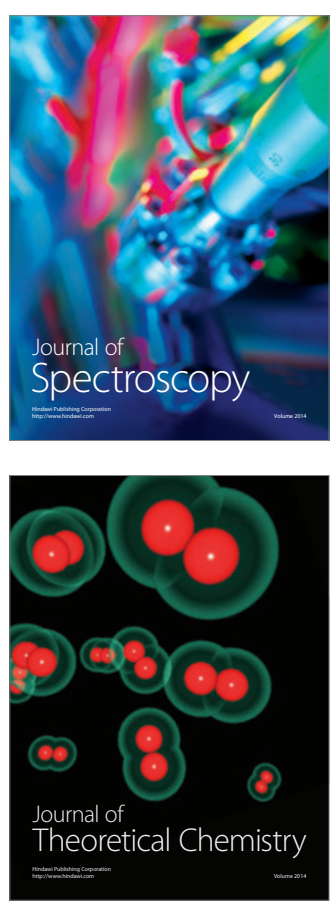
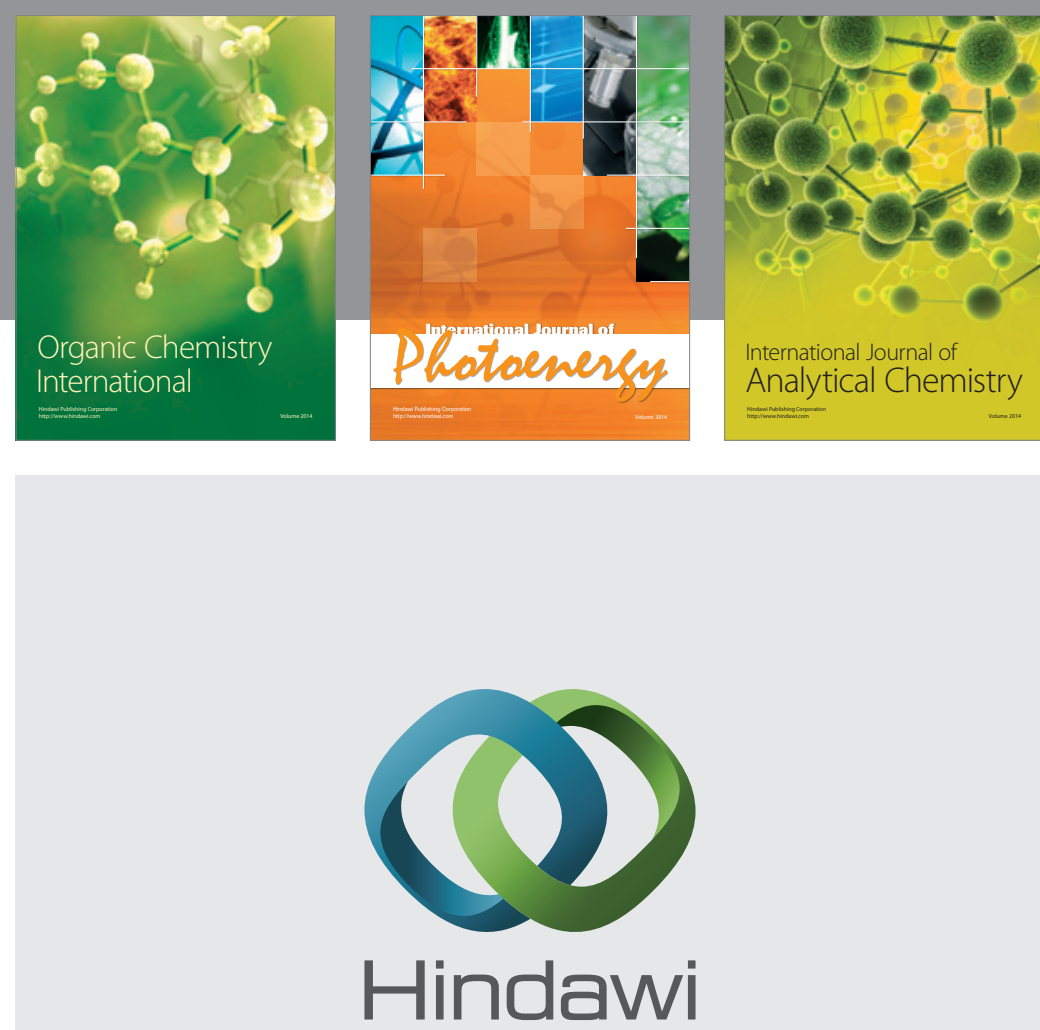

Submit your manuscripts at

http://www.hindawi.com
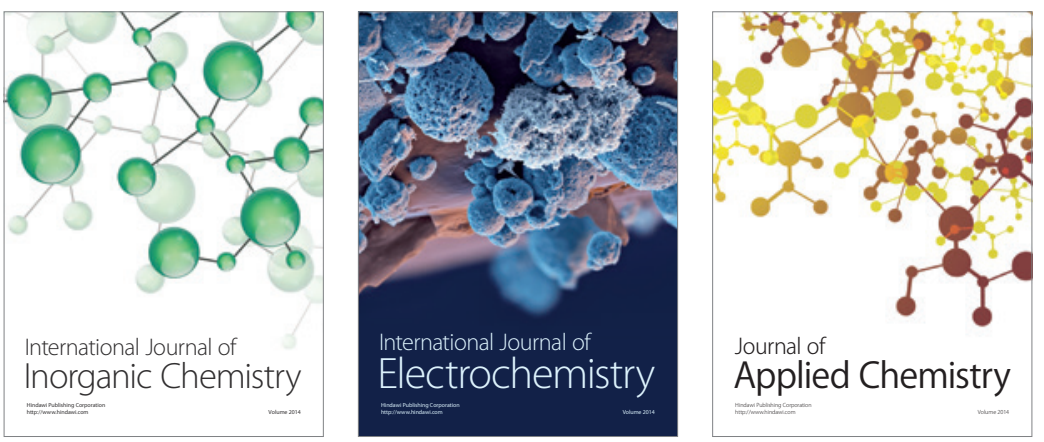

Journal of

Applied Chemistry
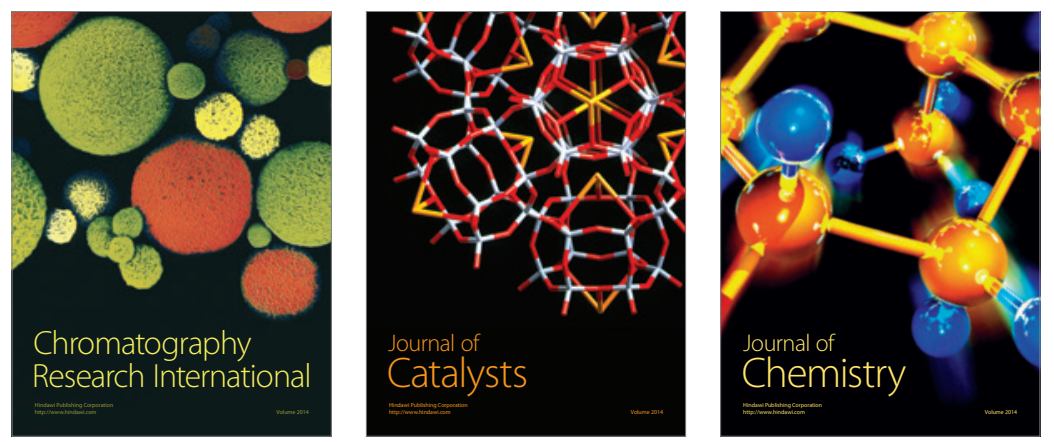
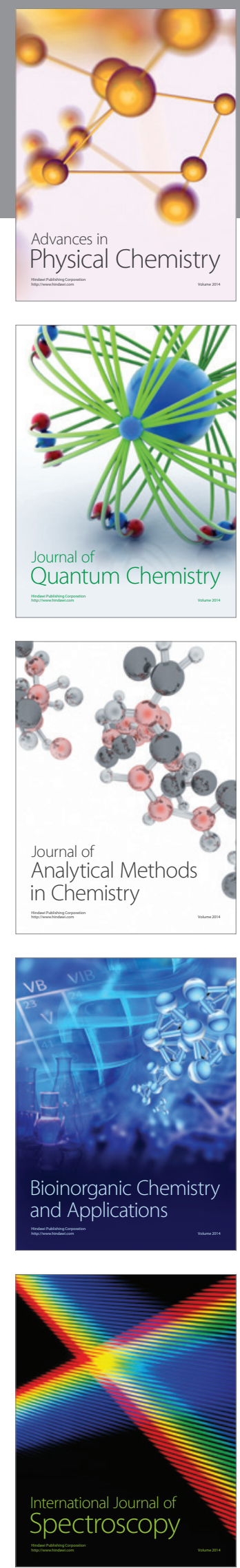